\title{
Reduction in Content of Bromine Compounds in the Product Oil of Pyrolysis Using Synthetic Hydrotalcite
}

\author{
N. Morita, T. Wajima, and H. Nakagome
}

\begin{abstract}
Polystyrene plastic samples containing brominated flame-retardants (BR-PS) were pyrolyzed at $400{ }^{\circ} \mathrm{C}$ using hydrotalcite to reduce the content of bromine compounds in the oil produced, in comparison with using sand, zeolite-4A, and zeolite-13X. The bromine plastic sample was prepared by mixing tetrabromobisphenol $A$ and polystyrene, and added to a glass reactor, together with hydrotalcite, sand, zeolite-4A, or zeolite-13X. The product oil obtained by pyrolysis at $400{ }^{\circ} \mathrm{C}$ from the BR-PS was mainly composed of aromatic compounds, such as benzene, heptane, and toluene, and two bromine compounds, 2-methyl-2-bromopentane and 3-bromopropane. The product oil obtained using hydrotalcite contained aromatic compounds with low molecular weight, and bromine compounds were not detected. In comparison with the use of sea sand and molecular sieves, the amount of bromine compounds in residue decreased in the order of hydrotalcite > molecular sieves 13X > molecular sieves $4 \mathrm{~A}>$ sand. Hydrotalcite thus trapped bromine in residue during the pyrolysis of BR-PS.
\end{abstract}

Index Terms-Flame retardants, Polystyrene, Bromine compounds, hydrotalcite, pyrolysis.

\section{INTORODUCTION}

Plastics are widely used in various products, such as electrical equipment. Such products constitute large amounts of waste at the end of their lives. In recent years, the recycling technology of plastics has developed to the level that a recycling society has emerged. A variety of recycling techniques have been used in recycling waste plastic, of which pyrolysis is one of the most promising. In pyrolysis, plastic polymers are converted into gas, oil, and carbon residue for uses such as chemical feedstock and fuel [1].

There is abundant literature on the chemical recycling of waste plastics and basic research on thermal decomposition, especially using catalyst [2]-[13]; e.g., the yield of product oil via plastic pyrolysis can be increased using ZSM-5 zeolite, red mud and mesoporous molecular sieves [14], [15]. However, plastics from electrical waste contain toxic brominated flame retardants, which pose a problem particularly for recycling [16]-[20]. For example, the treatment of brominated compounds from 300 to $500{ }^{\circ} \mathrm{C}$ results in the possible formation of brominated dibenzodioxins and furans [21]. This should be avoided because of the carcinogenic character of these products. Moreover, the production of hazardous byproducts reduces the acceptance of recycling processes by society.

There has been research into the preventing the release of

Manuscript received September 5, 2014; revised November 12, 2014.

Naoyuki Morita is with the Department of Urban Environment Systems, Graduate School of Engineering, Chiba University, Japan (e-mail: Naoyuki_Morita@chiba-u.ne.jp). halogen gas into oil and gas phases by pyrolysis [22], especially using additives as catalyst. For example, it was reported that polybrominated compounds mixed with polypropylene, polyethylene, polystyrene, and polyvinyl chloride can be thermally decomposed using a carbon composite of calcium carbonate (calcium-C) [23]. It was also reported that the quality of the pyrolysis oil was improved using commercial hydrogenation catalyst DHC-8 [24].

In the present study, polystyrene containing bromine compounds was pyrolyzed at $400{ }^{\circ} \mathrm{C}$ using hydrotalcite (HT) as an additive. The HT is classified as a layered double hydroxide composed of metal complex hydroxide: $\left[\mathrm{M}^{2+}{ }_{1-x} \mathrm{M}^{3+}{ }_{x}(\mathrm{OH})_{2}\right]^{x+}\left[\left(\mathrm{A}^{n-}\right)_{x / n} \cdot n \mathrm{H}_{2} \mathrm{O}\right]^{x-}(x=0.2-0.33)$, where $\mathrm{M}^{2+}$ and $\mathrm{M}^{3+}$ are divalent $\mathrm{Mg}^{2+}$ and trivalent $\mathrm{Al}^{3+}$ metal ions, respectively, and $\mathrm{A}^{n-}$ is an anionic species [25]. The structure of HT is a positively charged brucite-like octahedral layer and a negatively charged interlayer containing anions and water molecules [26]. HT has received increasing attention in recent years as an ion exchanger [27]-[29], catalyst [30], [31] and a material for gas removal [32], [33]. However, there have been no studies on the pyrolysis of waste plastics with bromine compound using hydrotalcite. Additionally, for comparison, plastics with bromine compounds were pyrolyzed using sea sand and molecular sieves, which are popular additives in the pyrolysis of plastics. We investigated the effect of hydrotalcite on the pyrolysis of plastics with bromine compound.

\section{EXPERIMENTAL}

\section{A. Materials}

Plastic samples containing bromine (BR-PS) were prepared by mixing $20 \mathrm{~g}$ of PSJ polystyrene (PS) (Asahi Kasei Chemicals Corporation Co., Ltd.) and $2 \mathrm{~g}$ of tetrabromobisphenol A (TBBA) (Tokyo Chemical Industry Co., Ltd., Tokyo, Japan). The elemental composition of the BR-PS, which was calculated from chemical compositions of each reagent, is given in Table I.

TABLE I: ELEMENTAL COMPOSITION OF THE BR-PS

\begin{tabular}{cc}
\hline \hline \multicolumn{2}{c}{ Elemental composition (wt. \%) } \\
\hline Carbon & 85.9 \\
Hydrogen & 10.8 \\
Bromine & 3.0 \\
Oxygen & 0.28 \\
Silicon & 0.02 \\
\hline \hline
\end{tabular}

To reduce bromine compounds in the product oil, synthetic hydrotalcite, KW-1000, (Kyowa Chemical Industry Co., Ltd.), 
sea sand (Wako Pure Chemical Industries, Ltd.), molecular sieve 4A (Wako Pure Chemical Industries, Ltd.) and molecular sieve 13X (Wako Pure Chemical Industries, Ltd.) were used as additives. The experimental conditions are listed in Table II.

TABLE II: EXPERIMENTAL CONDITIONS IN THE STUDY

\begin{tabular}{cl}
\hline \hline & \multicolumn{1}{c}{ Experimental condition } \\
\hline I & PS + TBBA \\
II & PS + TBBA + Sea sand \\
III & PS + TBBA + Molecular sieve 4A \\
IV & PS + TBBA + Molecular sieve 13X \\
V & PS + TBBA + Hydrotalcite \\
\hline \hline
\end{tabular}

\section{B. Experimental Apparatus and Procedures}

The experimental apparatus used in this study is shown in Fig. 1. A 22-g quantity of BR-PS or a mixture of BR-PS (22 g) and additive $(20 \mathrm{~g})$ was added to a glass reactor. The reactor was purged with nitrogen gas at a flow rate of 50 $\mathrm{mL} / \mathrm{min}$ for $60 \mathrm{~min}$ to remove oxygen. After oxygen substitution, the flow of nitrogen gas was stopped and the pyrolysis experiment was performed. The temperature of the plastic bed was measured as the decomposition temperature and the reactor temperature was increased to the decomposition temperature $\left(400{ }^{\circ} \mathrm{C}\right)$ at a heating rate of 5 ${ }^{\circ} \mathrm{C} / \mathrm{min}$. The gases produced by pyrolysis were condensed through a cooling pipe and recovered. Non-condensable gases, which pass through the condenser, were collected in a gas pack via bubbling of alkaline aqueous solution. Residue remained in the reactor after pyrolysis. The mass balance of the pyrolysis products (oil, gas, and residue) was calculated after the experiment. The pyrolysis products obtained after experiments under each condition were analyzed.

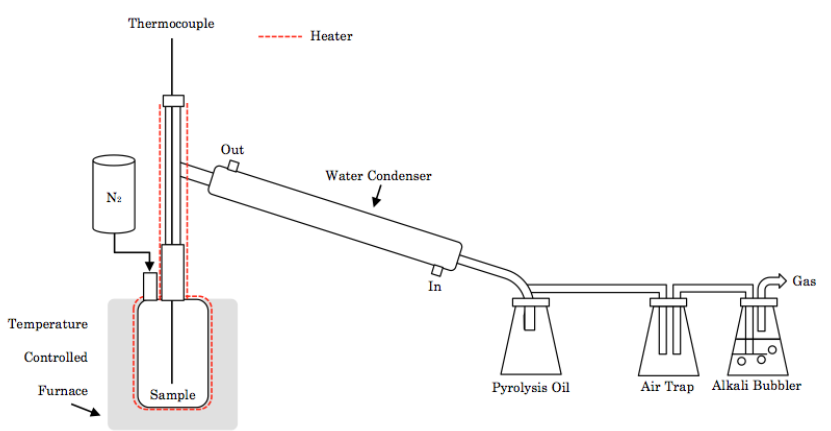

Fig. 1. Experimental apparatus.

\section{Analysis}

The oils were analyzed by gas chromatography/mass spectrometry (GC/MS) (Shimadzu, GC-MS-QP2010ultr) using an RTX-624 column (having thickness of $1.8 \mu \mathrm{m}$, an inner diameter of $60 \mathrm{~mm}$ and a length of $0.32 \mathrm{~mm}$ ) with pure helium as the carrier gas, and the main compounds in the oil were identified using a GC/MS spectral library. The analyses were performed at a temperature of $40{ }^{\circ} \mathrm{C}$ for 30 minutes, which was then increased to $230^{\circ} \mathrm{C}$ at a rate of $5^{\circ} \mathrm{C} / \mathrm{min}$. The structural change of the sample before and after the experiment was determined by X-ray diffraction analysis (Bruker, D2PHASER), and the morphologies of the sample before and after the experiment were observed with a scanning electron micrograph (SEM) (Hitachi High-Tech, TM3030). The alkaline aqueous solution in the bubbler trapped bromine in non-condensed gases, and bromine trapped in the bubbling solution was analyzed by ion chromatography (Shimadzu, HIP-SP). The product gas that passed through the alkaline aqueous solution was recovered by a gas pack and then analyzed using a Shim-pack column (150 mm (length) $\times 4.6 \mathrm{~mm}$ (inner diameter)) and a CDD-10Asp detector as part of a high-performance liquid-chromatography ion chromatography system.

\section{RESULTS AND DISCUSSION}

\section{A. Mass Balance of the Product}

The product yields under each experimental condition are given in Table III. Without an additive, the yields of product oil, residue and gas were $71.0,28.8$ and $0.2 \%$, respectively. When applying an additive, the yield of oil was the highest and that of residue was the lowest in the case of hydrotalcite. It is noted that the gas yields were lower than $1.1 \%$ under all conditions, revealing that gas was hardly generated in the pyrolysis of BR-PS.

TABLE III: PRODUCT YIELDS (WT.\%) UNDER EACH EXPERIMENTAL

\begin{tabular}{cccc} 
& \multicolumn{3}{c}{ CONDITION } \\
\hline & Oil & Residue & Gas \\
\hline I & 71.0 & 28.8 & 0.2 \\
II & 54.1 & 45.2 & 0.7 \\
III & 68.6 & 31.4 & 0.0 \\
IV & 70.9 & 29.1 & 0.0 \\
V & 83.9 & 15.0 & 1.1 \\
\hline \hline
\end{tabular}

\section{B. Analysis of the Oil Product}

Components of the product oil are given in Table IV. All oil products mainly contain toluene and benzene. Components of the product oil obtained under condition I are mainly aromatic compounds, such as benzene, 1-heptene, heptane, 1-methyl-2-methylene-cyclopentane, 3-methyl-cyclooctene, 2,4-dimethyl-hexene, dimethyloctene, 2-methyloctane, 3-methylheptane, 6-methyl-2-heptane, 1-methylcyclohexene, 3-methyl-2-cyclohexen-1-ol, 2-methyl-1-heptene and toluene, and two bromine compounds, 2-bromo-2-methylpropane and 3-bromo-pentane were detected.

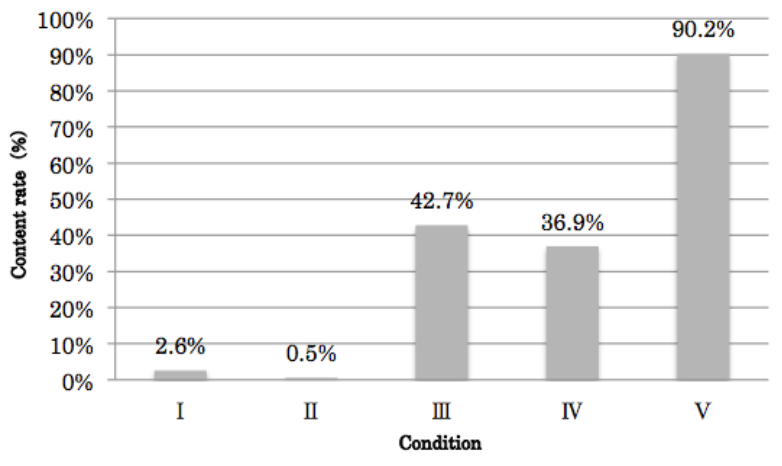

Fig. 2. Bromine contents of the residues under each condition.

The results in Table IV show that bromine compounds were not detected in the oil produced under condition V. It is noted that the oils produced under conditions II, IV and V had lower molecular weight than those under conditions I and III, which means that the addition of sea sand, molecular sieves 
$13 \mathrm{X}$ and hydrotalcite promotes the decomposition of compounds with high molecular weight into compounds with low molecular weight.

\section{Bromine Compounds of Residue}

Bromine contents of the residue obtained under each condition are given in Fig. 2. The bromine content in the residue was $2.6 \%$ without an additive and $0.5 \%$ using sea sand. With the addition of molecular sieves, the bromine content in the residue was $35-45 \%$, which was higher than the contents under conditions I and II. Furthermore, the bromine content in the residue obtained using hydrotalcite was $90.2 \%$, which was the highest achieved in this experiment. It is considered that bromine was trapped in the residue by the hydrotalcite, and the bromine compound was not included in the produced oil, as shown in Table IV.

TABLE IV: COMPONENTS OF PRODUCT OILS OBTAINED UNDER EACH EXPERIMENTAL CONDITION

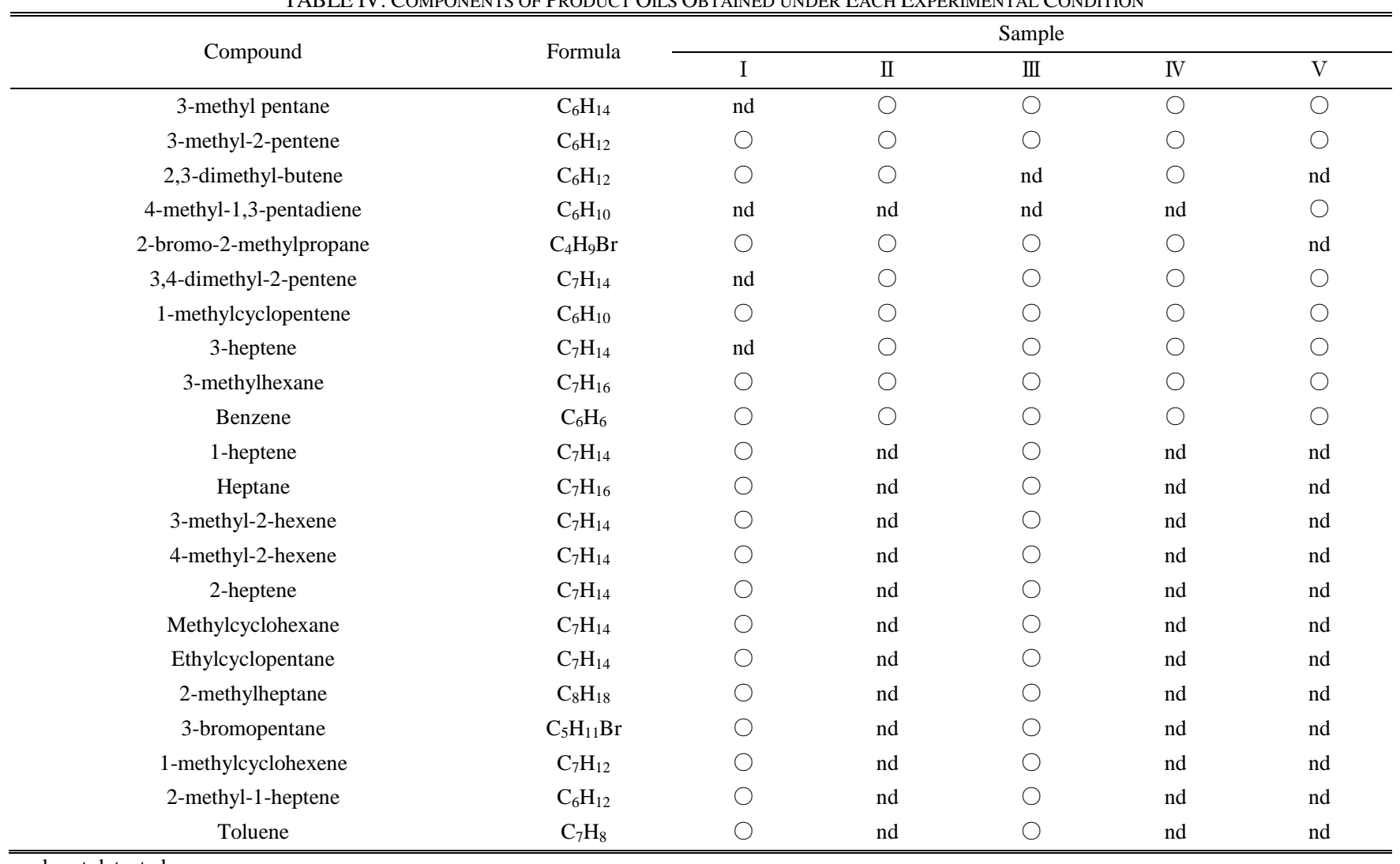

nd: not detected

X-ray diffraction patterns before and after the experiment conducted under condition $\mathrm{V}$ is shown in Fig. 3. Before the experiment, peaks of hydrotalcite, TBBR and PS were identified. After the experiment, these peaks disappeared, and new peaks corresponding to the oxides $\mathrm{MgAl}_{2} \mathrm{O}_{4}$ and $\mathrm{MgAlSi}{ }_{4} \mathrm{O}_{10}(\mathrm{OH}) \cdot 4 \mathrm{H}_{2} \mathrm{O}$ appeared, owing to the formation of these oxides from hydrotalcite and silica in PS.

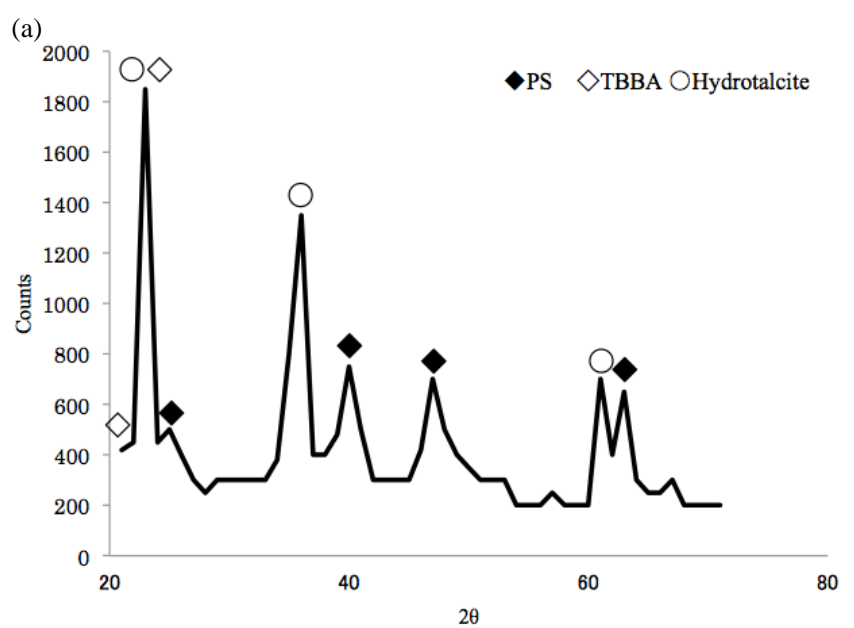

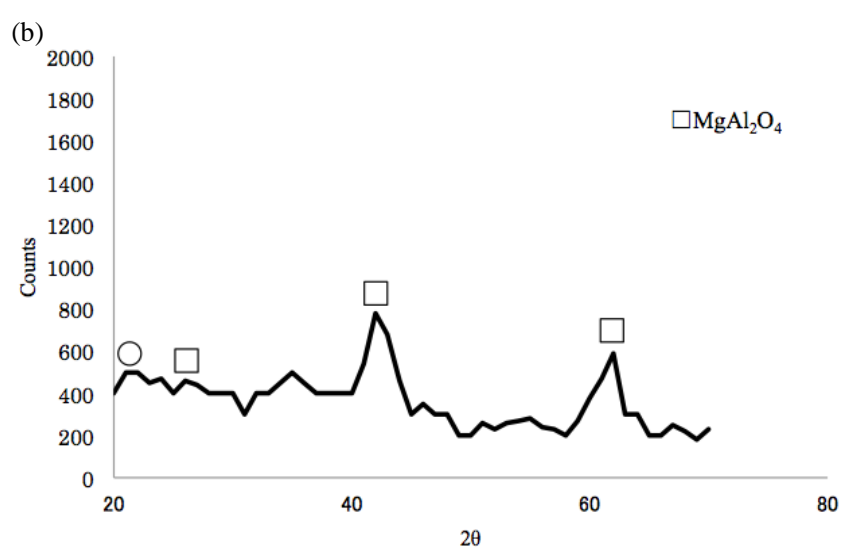

Fig. 3. X-ray diffraction patterns of the samples (a) before and (b) after the experiment conducted under condition $\mathrm{V}$.

SEM images of the sample (a) before and (B) after the experiment are shown in Fig. 4. Many particles were observed before the experiment and large particles with small particles on their surfaces were observed after the experiment. It may be considered that large particles are $\mathrm{Mg}$ - $\mathrm{Al}$ oxides and small particles, which may be bromine compounds, were adsorbed and precipitated on the surface of oxides. 
(a)

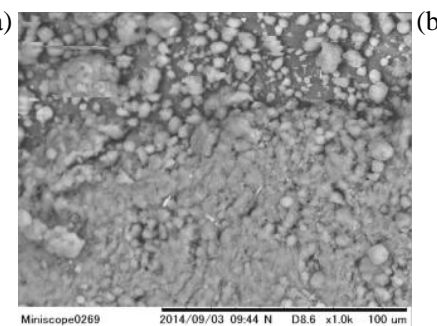

Miniscope0269
Fig. 4. SEM image of the sample (a) before and (b) after the experiment conducted under condition $\mathrm{V}$.

\section{Gas Production}

Bromine contents of the gas under each condition are given in Table V. The bromine content in $20 \mathrm{~g}$ of BR-PS was 1843 $\mathrm{mg}$, and the content in the gas phase was $0-0.9 \mathrm{mg}$. Therefore, bromine was mainly distributed in the residue and product oil by pyrolysis in this experiment.

The amounts of $\mathrm{CO}_{2}, \mathrm{CH}_{4}, \mathrm{C}_{3} \mathrm{H}_{6}$ and $\mathrm{C}_{3} \mathrm{H}_{8}$ in the productive gas are given in Table VI. Gases with high molecular weight were produced without an additive but not detected with an additive. It is noted that $\mathrm{CO}_{2}$ in the gas originated from $\mathrm{CO}_{2}$ in the layered structure of hydrotalcite.

TABLE V: BROMINE CONTENT IN GAS UNDER EACH CONDITION

\begin{tabular}{cc}
\hline \hline & Bromine content $(\mathrm{mg})$ \\
\hline I & 0.3 \\
II & 0.0 \\
III & 0.7 \\
IV & 0.9 \\
V & 0.4 \\
\hline \hline
\end{tabular}

TABLE VI: AMOUNTS OF $\mathrm{CO}_{2}, \mathrm{CH}_{4}, \mathrm{C}_{3} \mathrm{H}_{8}$ AND $\mathrm{C}_{3} \mathrm{H}_{6}$ IN THE GAS (WT. \%)

\begin{tabular}{ccccc}
\hline \hline & $\mathrm{CO}_{2}$ & $\mathrm{CH}_{4}$ & $\mathrm{C}_{3} \mathrm{H}_{8}$ & $\mathrm{C}_{3} \mathrm{H}_{6}$ \\
\hline I & nd & nd & 37.6 & 53.0 \\
II & nd & nd & nd & nd \\
III & nd & nd & nd & nd \\
IV & nd & nd & nd & nd \\
V & 0.2 & nd & nd & nd \\
\hline \hline
\end{tabular}

nd: not detected

\section{CONCLUSION}

We investigated methods of reducing the content of bromine compounds in product oil obtained by pyrolysis of bromine-based plastic. The oil produced from PS resin containing brominated flame retardants by pyrolysis using hydrotalcite did not contain bromine compounds. Additionally, the production yield of oil was greater and the capture of bromine in the residue was higher using hydrotalcite than using sea sand and molecular sieves. These results suggest that hydrotalcite is an excellent additive for oil production from waste plastics by pyrolysis.

\section{ACKNOWLEDGMENT}

This work was supported by Mr. Katsuhiro Hosaka and Mr. Noriyuki Suzuki of Tokyo Metropolitan Tama Science and Technology High School.

\section{REFERENCE}

[1] T. Bhaskar, T. Matsui, J. Kaneko, M. A. Uddin, A. Muto, and Y. Sakata, "Novel calcium based sorbent $(\mathrm{Ca}-\mathrm{C})$ for the dehalogenation $(\mathrm{Br}, \mathrm{Cl})$ process during halogenated mixed plastic (PP/PE/PS/PVC and HIPS-Br) pyrolysis," Green Chem, vol. 4, pp. 372-375, 2002.
[2] G. Grause, J. Ishibashi, T. Kameda, T. Bhaskar, and T. Yoshioka, "Kinetic studies of the decomposition of flame retardant containing high-impact polystyrene," Polym Degrad Stab, vol. 95, pp. 1129-1137, 2010 .

[3] J. A. Onwudili, N. Insura, and P. T. Williams, "Composition of products from the pyrolysis of polyethylene and polystyrene in a closed batch reactor: Effects of temperature and residence time," J Anal Appl Pyrolysis, vol. 86, pp. 293-303, 2009.

[4] W. J. Hall and P. T. Williams, "Fast pyrolysis of halogenated plastics recovered from waste computers," Energ Fuel, vol. 20, pp. 1536-1549, 2006.

[5] T. Bhaskar, M. A. Uddin, K. Murai, J. Kaneko, K. Hamano, T. Kusaba, A. Muto, and Y. Sakata, "Comparison of thermal degradation products from real municipal waste plastic and model mixed plastics," J Anal Appl Pyrolysis, vol. 70, pp. 579-587, 2003.

[6] D. P. Serrano, J. Aguado, J. M. Escola, and E. Garagorri, "Performance of a continuous screw kiln reactor for the thermal and catalytic conversion of polyethylene-lubricating oil base mixtures," Appl Catal $B$, vol. 44, pp. 95-105, 2003

[7] T. Bhaskar, T. Matsui, M. A. Uddin, J. Kaneko, A. Muto, and Y. Sakata, "Effect of $\mathrm{Sb}_{2} \mathrm{O}_{3}$ in brominated heating impact polystyrene (HIPS-Br) on thermal degradation and debromination by iron oxide carbon composite catalyst (Fe-C)," Appl Catal B, vol. 43, pp. 229-241, 2003.

[8] K. Murata, Y. Hirano, Y. Sakata, and M. A. Uddin, "Basic study on a continuous flow reactor for thermal degradation of polymers," J Anal Appl Pyrolysis, vol. 65, pp. 71-90, 2002.

[9] M. Blazso', Z. Cze'ge'ny, and C. Csoma, "Pyrolysis and debromination of flame retarded polymers of electronic scrap studied by analytical pyrolysis," J Anal Appl Pyrolysis, vol. 64, pp. 249-261, 2002

[10] H. Bockhorn, A. Hornung, U. Hornung, P. Jakobstro“er, and M. Kraus, "Dehydrochlorination of plastic mixtures," J Anal Appl Pyrolysis, vol. 49, pp. 97-106, 1999.

[11] M. Blazso' and E. Jakab, "Effect of metals, metal oxides, and carboxylates on the thermal decomposition processes of poly (vinyl chloride)," J Anal Appl Pyrolysis, vol. 49, pp. 125-143, 1999.

[12] R. Luijk, H. Haj, and L. Nelissen, "Formation of polybrominated dibenzofurans during extrusion of high-impact polystylene/decabromodiphenyl ether/antimony (III) oxide," Environ Sci Technol, vol. 26, pp. 2191-2198, 1992.

[13] Y. Uemichi, Y. Makino, and T. Kanazuka, "Degradation of polyethylene to aromatic hydrocarbons over metal-supported activated carbon catalysts," J Anal Appl Pyrolysis, vol. 14, pp. 331-344, 1989.

[14] A. López, I. de Marco, B. M. Caballero, M. F. Laresgoiti, A. Adrados, and A. Aranzabal, "Catalytic pyrolysis of plastic wastes with two different types of catalysts: ZSM-5 zeolite and Red Mud," Applied Catalysis B: Environmental vol. 104, pp. 211-219, 2011.

[15] C. Xie, F. Liu, S. Yu, F. Xie, L. Li, S. Zhang, and J. Yang, "Study on catalytic pyrolysis of polystyrene over base modified silicon mesoporous molecular sieve," Catalysis Communications, vol. 9, pp. 1132-1136, 2008.

[16] T. Bhaskar et al., "Effect of polyethylene terephthalate (PET) on the pyrolysis of brominated flame retardant-containing high-impact polystyrene (HIPS-Br)," J Mater Cycles Waste Manage, vol. 12, pp. 332-340, 2010.

[17] S. Peng et al., "Debromination of flame-retarded TV housing plastic waste," J Mater Cycles Waste Manage, vol. 12, pp. 103-107, 2010.

[18] P. S. Kulkarni, J. G. Crespo, and C. A. M. Afonso, "Dioxins sources and current remediation technologies-a review," Environ Int, vol. 34, pp. 139-153, 2008.

[19] C. Vasile, M. A. Brebu, T. Karayildirim, J. Yanik, and H. Darie, "Feedstock recycling from plastic and thermoset fractions of used computers (I): pyrolysis," J Mater Cycles Waste Manage, vol. 8, pp. 99-108, 2006.

[20] R. Luijk, H. Wever, K. Olie, G. Haj, and J. J. Boon, "The influence of the polymer matrix on the formation of polybrominated dibenzo-p-dioxins (PBDDs) and polybrominated dibenzofurans (PBDFs)," Chemosphere, vol. 23, pp. 1172-1183, 1991.

[21] T. Bhaskar, T. Matsui, J. Kaneko, M. A. Uddin, A. Muto, and Y. Sakata, "Novel calcium based sorbent $(\mathrm{Ca}-\mathrm{C})$ for the dehalogenation $(\mathrm{Br}, \mathrm{Cl})$ process during halogenated mixed plastic (PP/PE/PS/PVC and HIPS-Br) pyrolysis," Green Chem, vol. 4, pp. 372-375, 2002.

[22] X. Yang, L. Sun, J. Xiang, S. Hu, and S. Su, "Pyrolysis and dehalogenation of plastics from waste electrical and electronic equipment (WEEE): A review," Waste Management, vol. 33, pp. 462-473, 2013. 
[23] C. Vasile, M. A. Brebu, T. Karayildirim, J. Yanik, and H. Darie, "Feedstock recycling from plastics and thermosets fractions of used computers. II. Pyrolysis oil upgrading," Fuel, vol. 86, p. 477ff, 2007.

[24] Research Association for Feedstock Recycling of Plastics Japan, Base and Application of Plastic Recycling, CMC BOOKS, Japan 2012, p. $44 \mathrm{ff}$.

[25] T. Kwon, G. A. Tsigdinos, and T. J. Pinnavaia, "Pillaring of layered double hydroxides (LDH's) by polyoxometalate anions," J. Am. Chem. Soc., vol. 110, pp. 3653-3654, 1988.

[26] S. Miyata, "The syntheses of hydrotalcite-like compounds and their structures and physico-chemical properties I: The systems $\mathrm{Mg}^{2+}-\mathrm{Al}^{3+}-\mathrm{NO}_{3}^{-}, \mathrm{Mg}^{2+}-\mathrm{Al}^{3+}-\mathrm{Cl}^{-}, \mathrm{Mg}^{2+}-\mathrm{Al}^{3+}-\mathrm{ClO}_{4}^{-}, \mathrm{Ni}^{2+}-\mathrm{Al}^{3+}-\mathrm{Cl}^{-}$and $\mathrm{Zn}^{2+}-\mathrm{Al}^{3+}-\mathrm{Cl}^{-}$," Clays Clay Miner., vol. 23, pp. 369-375, 1975.

[27] T. Kameda, M. Nakamura, and T. Yoshioka, "Removal of antimonate ions from an aqueous solution by anion exchange with magnesium-aluminum layered double hydroxide and the formation of a brandholzite-like structure," Journal of Environmental Science and Health, Part A, vol. 47, pp. 1146-1151, 2012.

[28] T. Kameda, K. Hoshi, and T. Yoshioka, "Uptake of $\mathrm{Sc}^{3+}$ and $\mathrm{La}^{3+}$ from aqueous solution using ethylenediaminetetraacetate-intercalated $\mathrm{CuAl}$ layered double hydroxide reconstructed from $\mathrm{CuAl}$ oxide," Solid State Sciences, vol. 13, pp. 366-371, 2011.

[29] K. Ralla, U. Sohling, K. Suck, F. Sander, C. Kasper, F. Ruf, and T. Scheper, "Adsorption and separation of proteins by a synthetic hydrotalcite," Colloids and Surfaces B, Biointerfaces, vol. 87, pp. 217-225, 2011
[30] E. Suzuki, M. Okamoto, and Y. Ono, "Catalysis by interlayer anions of a synthetic hydrotalcite-like mineral in a halide exchange between organic halides," Chem. Lett., vol. 18, pp. 1485-1486, 1989.

[31] K. J. Martin and T. J. Pinnavaia, "Layered double hydroxides as supported anionic reagents. Halide-ion reactivity in zinc chromium hexahydroxide halide hydrates $\left[\mathrm{Zn}_{2} \mathrm{Cr}(\mathrm{OH})_{6} \mathrm{X} . \mathrm{nH}_{2} \mathrm{O}\right](\mathrm{X}=\mathrm{Cl}, \mathrm{I}), " J$. Am. Chem. Soc., vol. 108, pp. 541-542, 1986.

[32] T. Kameda, N. Uchiyama, T. Yoshioka, "Removal of $\mathrm{HCl}, \mathrm{SO}$, and NO by treatment of acid gas with $\mathrm{Mg}-\mathrm{Al}$ oxide slurry," Chemosphere, vol. 82, pp. 587-591, 2011.

[33] T. Kameda, N. Uchiyama, and T. Yoshiok, "Treatment of gaseous hydrogen chloride using $\mathrm{Mg}$ - $\mathrm{Al}$ layered double hydroxide intercalated with carbonate ion," Chemosphere, vol. 80, pp. 658-662, 2010.

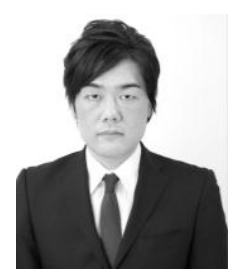

Naoyuki Morita was born in Japan in 1977. He graduated from Chiba University in 2011 and is now studying at the Department of Urban Environment System at Chiba University, Japan. 